\title{
Pengaruh Citra Merek dan Kualitas Produk Serta Desain Produk Terhadap Keputusan Pembelian Smartphone Oppo di Badilan Grosir Singaraja
}

\author{
Ni Kadek Deni Karmini Yanti ${ }^{\star 1}$, Ni Luh Wayan Sayang Tegagawathi ${ }^{2}$ \\ 1,2 Program Studi Manajemen \\ Universitas Pendidikan Ganesha \\ Singaraja, Indonesia
}

\section{e-mail: denikarminiyanti05@gmail.com¹,gemilangsuryawan@gmail.com²}

\section{Riwayat Artikel Tanggal diajukan: 19 Maret 2021 \\ Tanggal diterima: 23 November 2021 \\ Tanggal dipublikasikan: 15 Desember 2021}

Pengutipan: Karmini, Y. N. K. D., \& Sayang, $T$. N. L. W. (2021). Pengaruh Citra Merek dan Kualitas Produk Serta Desain Produk Terhadap Keputusan

Pembelian Smartphone Oppo di Badilan Grosir Singaraja. Jurnal Pendidikan Ekonomi

Undiksha, 13(2), 276-284

http://dx.doi.org/1 $\underline{0.23887 / j j p e . v 13 i}$ 2.33189

\begin{abstract}
Abstrak
Penelitian ini bertujuan untuk menguji pengaruh citra merek dan kualitas produk serta desain produk terhadap keputusan pembelian, baik itu secara simultan maupun secara parsial. Desain penelitian yang digunakan dalam penelitian ini yaitu Kuantitatif kausal. Subjek dala penelitian ini yaitu konsumen yang memiliki Smartphone Oppo dan membelinya di Badilan Grosir Singaraja dan objek penelitian ini adalah citra merek, kualitas produk, desain produk dan keputusan pembelian. sampel dalam penelitian ini berjumlah 100 responden. Data yang dikumpulkan dengan kuesioner dan dianalisis dengan menggunakan analisis regresi linier berganda. Hasil penelitian menunjukan bahwa (1) citra merek dan kualitas produk serta desain produk berpengaruh positif dan signifikan terhadap keputusan pembelian (2) citra merek berpengaruh positif dan signifikan terhadap keputusan pembelian (3) dan kualitas produk berpengaruh positif dan signifikan terhadap keputusan pembelian (4) desain produk berpengaruh positif dan signifikan terhadap keputusan pembelian Smartphone Oppo di Badilan Grosir Singaraja.
\end{abstract}

Kata Kunci: Citra Merek; Desain Produk; Keputusan Pembelian; Kualitas Produk

\begin{abstract}
This research aims to examine the effect of brand image and product quality as well as product design on purchasing decision, either simultaneously or partially. The research design used in this research is causal quantitative. The subjects in this research are consumers who own an Oppo Smartphone and buy it at Badilan Grosir Singaraja and the objects of this research are brand image, product quality, product design and purchase decisions. The sample in this study amounted to 100 respondents. The data were collected by means of a questionnaire and analyzed using multiple linear regression analysis. The results showed that (1) brand image and product quality and product design had a positive and significant effect on purchasing decisions (2) brand image had a positive and significant effect on purchasing decisions (3) and product quality had a positive and significant effect on purchasing decisions (4) Product design has a positive and significant effect on the purchase decision of an Oppo Smartphone at Badilan Grosir Singaraja.
\end{abstract}

Keywords : Brand Image; Product Design; Purchase Decisions; Product Quality 


\section{PENDAHULUAN}

Teknologi di Negara Indonesia mengalami kemajuan yang signifikan secara terus menerus. Perihal tersebut ditandai dengan munculnya berbagai jenis alat komunikasi yang canggih salah satunya adalah Smartphone yang dijadikan sebagai alat perantara komunikasi oleh pelaku usaha dan masyarakat pada umumnya. $\mathrm{Di}$ bidang perangkat komunikasi, Smartphone menjadi kebutuhan primer bagi setiap orang. Mengenai munculnya hal tersebut, tentunya akan sangat berdampak pada meningkatnya permintaan akan alat komunikasi oleh masyarakat, sehingga memicu terjadinya persaingan antar pelaku usaha Smartphone. Pola pikir yang baru muncul karena adanya persaingan dalam dunia bisnis agar dapat menciptakan barang atau jasa untuk menyampaikan nilai lebih kepada pelanggan (Subhash, 2017).

Para pelaku usaha dituntut untuk mampu membuat ide-ide baru baik dari segi kualitas produk, citra merek, dan desain produk Smartphone. Smartphone didefinisikan sebagai sebuah telepon genggam yang juga diartikan sebagai komputer genggam karena pengoperasiannya menyerupai komputer dan memiliki fasilitas telepon serta karakteristik atau kemampuan tingkat tinggi (Margono, 2010). Selain itu, Smartphone merupakan alat komunikasi yang memiliki pengaruh besar dalam melakukan aktivitas sehari-hari, seperti media bisnis, media hiburan, media informasi dan media edukasi dan lain-lainnya.

Produk Smartphone sudah tersebar luas di berbagai wilayah Indonesia. Penyebaran produk tersebut terus meningkat dan hampir terdapat disemua wilayah yang terdapat di Indonesia yaitu Provinsi Bali. Seiring dengan hal tersebut, banyak perusahaan-perusahaan digital di Bali yang menyediakan berbagai jenis merek Smartphone untuk memenuhi kebutuhan masyarakat. Adapun jenis Smartphone yang disediakan oleh outletoutlet Smartphone seperti merek Samsung, Oppo, Xiaomi, Vivo, Asus, Lenovo, Iphone, dan lainnya. Melihat hal tersebut kebutuhan masyarakat dapat terpenuhi. Salah satu Smartphone yang memiliki kualitas dan citra merek serta desain yang sedang trend saat ini adalah Smartphone Oppo. Merek Oppo dapat dikatakan sebagai merek baru yang mampu bersaing dengan merek Smartphone lainnya seperti Vivo, dan Xiaomi. Smartphone Oppo memperkenalkan produknya dengan melalui iklan di TV hal tersebut bertujuan untuk memberikan informasi serta menarik perhatian masyarakat, dan juga bekerjasama dengan perusahaan penjual Smartphone melalui pemasangan banner atau spanduk agar merek Oppo menjadi banyak terkenal dikalangan masyarakat.

$$
\text { Badilan Grosir Singaraja }
$$

merupakan salah satu outlet penjual Smartphone lengkap dengan menyediakan berbagai jenis merek dan aksesoris Smartphone yang ada di Kabupaten Buleleng tepatnya beralamat di Jl. A.Yani No.89b, Kaliuntu, Kecamatan Buleleng, Kabupaten Buleleng, Bali. Selain itu, Badilan juga memiliki dua cabang outlet yang berlokasi di Kubutambahan dan Seririt. Badilan Grosir juga menyediakan toko resmi untuk memberikan pelayanan servis dan kemudahan bagi pelanggan ataupun masyarakat lainnya apabila memiliki masalah pada Smartphone nya.

Berdasarkan sumber data dari Badilan Grosir Singaraja bahwa penjualan Smartphone yang mengalami peningkatan setiap bulannya adalah Smartphone merek Oppo. Pada bulan Januari ke Februari jumlah penjualan Smartphone Oppo mengalami peningkatan sebesar $9,7 \%$, dan pada bulan Maret kembali mengalami peningkatan sebesar 10,8\%. Meskipun penjualan Smartphone Oppo mengalami peningkatan, tetapi belum memperoleh target penjualan yang sudah ditargetkan dari pihak Badilan Grosir Singaraja. Dimana dari pihak perusahaan mentargetkan penjualan Smartphone Oppo terjual sebanyak 800 produk untuk setiap bulannya. Hal ini menunjukan penjualan Smartphone Oppo dari bulan Januari sampai dengan Maret masih dibawah target penjualan. Untuk mencapai target penjualan diharapkan pihak perusahaan harus menjaga citra merek, dan meningkatkan kualitas produknya serta membuat desain produk yang lebih menarik 
agar dapat lebih mendorong daya tarik konsumen untuk membeli sehingga bisa dapat dicapai target penjulan.

Citra Merek salah satu variabel pertama yang mempunyai pengaruh terhadap kegiatan pembelian. Pembeli dapat membedakan beberapa produk dengan adanya citra merek produk. Citra merek adalah pikiran dan perasaan pelanggan ketika mendengar suatu merek (K. P. dan Amstrong, 2012). Produk yang mempunyai suatu citra baik tentunya akan mendorong pembeli untuk mengkonsumsinya. Barang yang mempunyai suatu citra yang baik tentunya mendorong pembeli untuk mengkonsumsinya. Citra merek yang unik dan berbeda menjadi hal penting apabila citra mengenai merek berkaitan dengan tingkah laku dalam bentuk kepercayaan dan referensi terhadap sebuah merek. Hal tersebut sejalan dengan temuan yang dilaksanakan oleh Yustiawan (2016), mengemukakan bahwa variabel citra merek berdampak positif dan relevan pada variabel keputusan pembelian. Hasil riset itu didukung pula oleh penelitian S \& Aloan (2017), memaparkan bahwa citra merek mempunyai dampak signifikan pada variabel Y. Namun berbeda dengan hasil penelitian Lubis \& Hidayat (2017), mendeskripsikan ternyata citra merek tidak memiliki dampak pada variabel keputusan pembelian.

Pengambilan keputusan juga dapat dipengaruhi oleh variabel kualitas produk. Kualitas produk merupakan kinerja produk untuk menampilkan kegunaanya seperti keseluruhan masa kegunaan dari produk, kesederhanaan, keandalan, mudah dalam perbaikan dan pengoperasian (K. P. dan Amstrong, 2012).Farisi (2018), juga memaparkan bahwa kualitas produk memberi dampak positif dan relevan pada variabel keputusan pembelian. Selanjutnya pada penelitian Mukarromah \& R (2019), mengemukakan bahwa kualitas produk memberi dampak positif dan relevan pada keputusan pembelian. Hal ini berbeda dengan hasil temuan yang dikemukakan Syamsidar \& Soliha (2019), memaparkan variabel kualitas produk tidak memberikan dampak yang relevan pada variabel keputusan pembelian.
Selain kualitas produk, variabel desain produk dapat memberikan pengaruh kepada pembeli untuk melakukan keputusan pembelian. Desain merupakan tahap awal yang digunakan oleh perusahaan sebelum memulai membuat suatu barang. Sehingga mampu dikatakan bahwa desain adalah bentuk perumusan dari bermacam unsur termasuk berbagai perhitungan yang perlu diperhatikan didalamnya. Menurut Kotler \& Keller (2012), desain produk yaitu fungsi keseluruhan yang mendorong performa, fungsi produk atau jasa berdasarkan keperluan para konsumen. Aspek desain produk dalam aktivitas pemasaran yaitu menjadi sebuah ketentuan yang mampu menciptakan daya tarik kepada sebuah produk. Hasil penelitian Tengor (2016), memaparkan ternyata desain produk memberikan pengaruh relevan kepada variabel keputusan.Amron (2018), memamparkan ternyata dari hasil variabel desain produk berdampak positif dan relevan pada variabel keputusan pembelian. Terdapat perbedaan temuan yang dikemukakan oleh Maindoka et al., (2018), menjelaskan desain produk ternyata tidak berdampak pada variabel keputusan pembelian.

Adapun gap atau kesenjangan temuan yang timbul mengacu pada temuan tentang Citra Merek dan Kualitas Produk serta Desain Produk pada Keputusan Pembelian yang berbeda-beda menjadi dasar penelitian yang dilakukan, temuan ini dilaksanakan dengan maksud menguji kembali dampak citra merek dan kualitas produk serta desain produk pada keputusan pembelian. Dipilihnya Smartphone Oppo karena dilihat dari gep fenomena Smartphone Oppo merupakan Smartphone yang paling diminati oleh masyarakat hal tersebut didukung oleh data penjualan di Badilan Grosir Singaraja.

Merujuk pada Latar Belakang temuan yang sudah dibahas sebelumnya, terdapat rumusan masalah pada temuan ini yaitu : (1) Apakah ada dampak dari citra merek pada keputusan pembelian Smartphone Oppo di Badilan Grosir Singaraja, (2) Apakah ada dampak dari kualitas produk pada keputusan Smartphone Oppo di Badilan Grosir 
Singaraja, (3) Apakah ada dampak dari desain produk pada keputusan pembelian Smartphone di pada Badilan Grosir Singaraja, (4) Apakah ada dampak dari citra merek dan kualitas produk serta desain produk pada keputusan pembelian pada pembelian Smartphone Oppo di Badilan Grosir Singaraja.

Adapun Tujuan dari temuan ini adalah agar mendaptkan hasil penelitian atau pemaparan teruji tentang (1) menguji dampak Citra Merek pada Keputusan Pembelian Smartphone Oppo di Badilan Grosir Singaraja (2) menguji dampak Kualitas Produk pada Keputusan Smartphone Oppo di Badilan Grosir Singaraja.(3) menguji dampak Desain Produk pada Keputusan Smartphone Oppo di Badilan Grosir Singaraja (4) menguji dampak $X_{1}$ dan $X_{2}$ serta $X_{3}$ pada Keputusan Pembelian Smartphone Oppo di Badilan Grosir Singaraja.

\section{METODE}

Jenis penelitian yang digunakan adalah riset kuantitatif. Untuk desain temuan yang dipakai dalam penelitian ini yaitu desain temuan kausal. Desain Kausal ini dipergunakan agar mampu mengetahui keterkaitan sebab akibat antara variabel $X$ dan variabel Y (Sugiyono, 2014). Dilakukannya temuan ini untuk mengetahui hubungan variabel citra merek dan kualitas produk serta desain produk terhadap keputusan pembelian Smartphone Oppo di Badilan Grosir Singaraja. Adapun langkahlangkah dalam penelitian kuantitatif kausal yang terdiri dari (1) rumusan masalah, (2) mengkaji teori, (3) merumuskan hipotesis, (4) mengumpulkan data, (5) mengolah data dan (6) membuat simpulan.

Untuk sampel penelitian metode yang dipakai pada temuan ini yaitu purposive sampling. Dimana purposive sampling dapat diartikan sebagai cara penentuan atau pemilihan sampel melalui tujuan dan penyesuaian tertentu (Sugiyono, 2007). Adapun kategori responden yang dipakai sampel yaitu diantaranya (1) Pembeli atau pelanggan yang memakai dan membeli Smartphone Badilan Grosir Singaraja. Hasil perhitungan statistic dilakukan dengan memasukkan data dari setiap variabel baik itu bebas atau
Oppo di Badilan Grosir Singaraja, (2) Pembeli atau pengguna Smartphone Oppo dapat dipilih sebagai responden yaitu yang berumur 20 - 60 tahun. Pemilihan responden berdasarkan usia yang sudah dianggap dewasa dan dianggap telah mampu menjawab pertanyaan yang diajukan oleh peneliti. Parameter yang diestimasi menentukan banyaknya sampel yang digunakan. Menurut Ferdinand (2006), acuannya yaitu banyaknya sampel yaitu 5-10 dikali banyak indikator dan 5-10 kali jumlah parameter yang diestimasi. Total indikator yang pakai dalam penelitian berjumlah 17 indikator. Maka pengambilan sampel minimal adalah $17 \times 5=85$ dan maksimal adalah $17 \times 10=170$. Oleh sebab itu, total responden yang dipakai pada temuan ini sebanyak 100 orang.

Metode akumulasi data pada temuan ini melalui kuesioner. Menurut Sugiyono (2007), kuesioner dapat diartikan sebagai salah satu metode akumulasi data yang akan dijawab oleh responden melalui mengajukan beberapa pernyataan ataupun pertanyaan yang tertulis. Untuk teknik ulasan data yang dipakai yaitu analisis regresi linier berganda. Analisis regresi linier berganda merupakan analisis yang dipakai agar bisa memahami besarnya keterkaitan dan dampak langsung atau tidak langsung dari citra merek $\left(\mathrm{X}_{1}\right)$ dan kualitas produk $\left(X_{2}\right)$ serta desain produk $\left(\mathrm{X}_{3}\right)$ terhadap keputusan pembelian $(\mathrm{Y})$ Smartphone pada Badilan Grosir Singaraja. Alasan penemu menjadikan analisis regresi linier berganda karena dalam temuan ini menguji pengaruh dari beberapa variabel bebas yaitu citra merek $\left(X_{1}\right)$ dan kualitas produk $\left(X_{2}\right)$ serta desain produk $\left(X_{3}\right)$ terhadap satu variabel terikat adalah keputusan pembelian (Y).

\section{HASIL DAN PEMBAHASAN}

Dengan Analisis Regresi Linier Berganda yang dipakai pada temuan ini, bermksud untuk memahami pengaruh Citra merek (X1) dan Kualitas Produk (X2) serta Desain Produk (X3) pada Keputusan Pembelian (Y) Smartphone Oppo di

terikat. Perhitungan uji statistik ini menggunkan bantuan program (SPSS) 22.0 for Windows, hingga didapatkan nilai 
p-ISSN : 2599-1418

e-ISSN : 2599-1426

temuan dampak dari $X_{1}$ dan $X_{2}$ serta $X_{3}$ pada keputusan pembelian Smartphone
Jurnal Pendidikan Ekonomi Undiksha

Vol. 13 No. 2 (2021)

Oppo di Badilan Grosir Singaraja dapat merujuk dengan tabel 1.

Tabel.1

Rangkuman hasil Output Analisis Analisis Regresi Linier Berganda

\begin{tabular}{|c|c|c|c|c|c|}
\hline Parameter & Koefisien & p-value & Alpha & Keputusan & Kesimpulan \\
\hline$R_{y \times 1 \times 2 \times 3}$ & 0,907 & 0,000 & 0,05 & $\begin{array}{l}\text { Menolak } \\
\mathrm{HO}\end{array}$ & $\begin{array}{l}\text { Ada pengaruh simultan dari citra merek } \\
\left(\mathrm{X}_{1}\right) \text {,kualitas produk }\left(\mathrm{X}_{2}\right) \text { dan desain } \\
\text { produk }\left(\mathrm{X}_{3}\right) \text { terhadap keputusan } \\
\text { pembelian }(\mathrm{Y}) \text {. }\end{array}$ \\
\hline$R^{2}{ }_{y \times 1 \times 2 \times 3}$ & 0,822 & 0,000 & 0,05 & $\begin{array}{l}\text { Menolak } \\
\mathrm{HO}\end{array}$ & $\begin{array}{l}\text { Menunjukkan besarnya sumbangan } \\
\text { pengaruh secara simutan dari citra } \\
\text { merek }\left(X_{1}\right) \text {, kualitas produk }\left(X_{2}\right) \text { dan } \\
\text { desain produk }\left(X_{3}\right) \text { terhadap keputusan } \\
\text { pembelian }(Y) \text { sebesar } 82,2 \%\end{array}$ \\
\hline$P_{y x 1}$ & 0,267 & 0,008 & 0,05 & $\begin{array}{l}\text { Menolak } \\
\mathrm{HO}\end{array}$ & $\begin{array}{l}\text { Menunjukkan bahwa ada hubungan } \\
\text { pengaruh parsial dari citra merek } \\
\text { terhadap keputusan pembelian. }\end{array}$ \\
\hline$P^{2}{ }_{y x 1}$ & 0,071 & - & - & & $\begin{array}{l}\text { Menunjukkan bahwa besar sumbangan } \\
\text { pengaruh citra merek terhadap } \\
\text { keputusan pembelian sebesar } 0,071 \\
\text { atau } 7.1 \% \text {. }\end{array}$ \\
\hline$P_{y \times 2}$ & 0,417 & 0,000 & 0.05 & $\begin{array}{l}\text { Menolak } \\
\mathrm{HO}\end{array}$ & $\begin{array}{l}\text { Menunjukkan bahwa ada hubungan } \\
\text { pengaruh parsial dari kualitas produk } \\
\text { terhadap keputusan pembelian. }\end{array}$ \\
\hline$P^{2 y \times 2}$ & 0,174 & - & - & & $\begin{array}{l}\text { Menunjukkan bahwa besar sumbangan } \\
\text { pengaruh kualitas terhadap keputusan } \\
\text { pebelian sebesar } 0,174 \text { atau } 17,4 \% \text {. }\end{array}$ \\
\hline$P_{y \times 3}$ & 0,275 & 0,006 & 0,05 & $\begin{array}{l}\text { Menolak } \\
\mathrm{HO}\end{array}$ & $\begin{array}{l}\text { Menunjukkan bahwa ada hubungan } \\
\text { pengaruh parsial dari desain produk } \\
\text { terhadap keputusan pembelian. }\end{array}$ \\
\hline$P^{2} y \times 3$ & 0,076 & - & - & & $\begin{array}{l}\text { Menunjukkan besarnya sumbangan } \\
\text { pengaruh variable desain produk } \\
\text { terhadap keputusan pembelian sebesar } \\
0,076 \text { atau } 7,6 \% \text {. }\end{array}$ \\
\hline$\varepsilon$ & 0,178 & - & - & & $\begin{array}{l}\text { Besarnya pengaruh variable lain } \\
\text { terhadap keputusan pembelian sebesar } \\
17,8 \% \text {. }\end{array}$ \\
\hline$\propto$ & 1,022 & & & & $\begin{array}{l}\text { Bisa memprediksi keputusan pembelian } \\
\text { Smartphone Oppo di Badilan Grosir } \\
\text { Singaraja. }\end{array}$ \\
\hline$\beta_{1}$ & 0,276 & 0,008 & 0,05 & Signifikan & Bisa memprediksi variable citra merek. \\
\hline$\beta_{2}$ & 0,458 & 0,000 & 0,05 & Signifikan & $\begin{array}{l}\text { Bisa memprediksi variable kualitas } \\
\text { produk. }\end{array}$ \\
\hline
\end{tabular}




$$
\begin{aligned}
& \beta_{3} \quad 0,572 \quad 0,006 \quad 0,05 \text { Signifikan Bisa memprediksi variable desain } \\
& \text { produk. }
\end{aligned}
$$

\section{Sumber : Hasil data diolah SPSS}

Mengacu pada ringkasan hasil Output Analisis Regresi Linier Berganda di Tabel 1 sebelumnya, hingga bisa digambarkan struktur hubungan pengaruh $\left(X_{1}\right)$ dan $\left(X_{2}\right)$ serta $\left(\mathrm{X}_{3}\right)$ terhadap $(\mathrm{Y})$ digambarkan pada gambar 1 sebagai berikut :

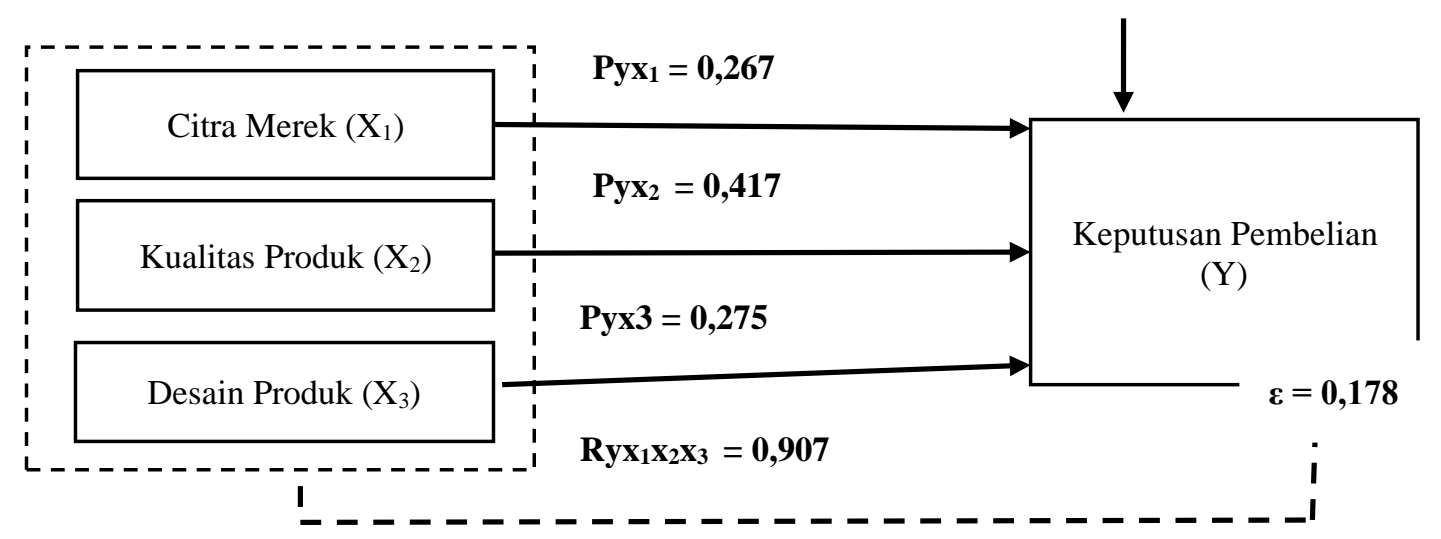

Gambar 1

Struktur Pengaruh variabel $\left(\mathrm{X}_{1}\right)$ dan $\left(\mathrm{X}_{2}\right)$ serta $\left(\mathrm{X}_{3}\right)$ terhadap variabel $(\mathrm{Y})$

Keterangan :

\section{Pengaruh Parsial}

Pengaruh Simultan

Mengacu pada gambar sebelumnya dari nilai analisis regresi linier berganda membuktikan ternyata nilai dari koefisien korelasi $\mathrm{Pyx}_{1}$ sebanyak 0,267 berarti $\neq 0$ dengan nilai $p$-value $0,008<$ alpha 0.05 dengan sumbangan pengaruh sebanyak 0,071 atau $7,1 \%$. Hal ini data disimpulkan bahwa secara individu $X_{1}$ mempunyai dampak posistif dan relevan pada keputusan pembelian Smartphone Oppo di Badilan Grosir Singaraja.

Selain itu, dapat juga dilihat bahwa nilai dari koefisien korelasi $\mathrm{Pyx}_{2}$ sebesar 0,417 , berarti $\neq 0$ dengan angka $p$-value $0,000<$ alpha 0.05 melalui sumbangan pengaruh sebanyak 0,174 atau $17,4 \%$. Hal ini dapat disimpulkan bahwa secara tersendiri kualitas produk berdampak posistif dan relevan pada keputusan pembelian Smartphone Oppo di Badilan Grosir Singaraja.

Gambar diatas juga menunjukan bahwa nilai dari koefisien korelasi $\mathrm{Pyx}_{3}$ sebesar 0,275 ,berarti $\neq 0$ dengan nilai $p$ value $0,000<$ alpha 0.05 melalui sumbangan pengaruh sebesar 0.076 atau 7,6\%. Sehingga dapat disimpulkan bahwa desain produk secara tersendiri memberikan dampak positif dan relevan pada kegiatan pembelian Smartphone Oppo di Badilan Grosir Singaraja.

Serta dapat dilihat pula bahwa nilai dari koefisien $\mathrm{Ryx}_{1} \mathrm{x}_{2}$ sebesar 0,907 berarti $\neq$ 0 dengan $p$-value $0,000<$ alpha 0,05 dengan sumbangan dampak sebanyak 0,822 atau $82,2 \%$. Maka dapat dirangkum ternyata citra merek dan kualitas produk serta desain produk bersama-sama memberikan dampak posistif dan relevan pada keputusan pembelian Smartphone Oppo di Badilan Grosir Singaraja.

Berdasarkan rekapan nilai akhir uji regresi linier berganda ditabel 1 menunjukan bahwa selain citra merek dan kualitas produk serta desain produk, ada variabel lain yang memberikan dampak keputusan pembelian yaitu nilai pada $\varepsilon$ sebesar 0.178 atau $17,8 \%$. Sehingga dapat disimpulkan bahwa keputusan pembelian juga 
p-ISSN : 2599-1418

e-ISSN : 2599-1426

disebabkan oleh variabel lain ssebesar $17,8 \%$ diluar variabel yang diuji apada temuaan ini.

\section{HASIL DAN PEMBAHASAN}

Hasil temuan membuktikan ternyata citra merek berdmpak positif dan relevan pada keputusan pembelian Smartphone Oppo di Badilan Grosir Singaraja. Hal tersebut sama terkait teori yang dipaparkan Shimp (2003), citra merek yang baik pada suatu produk dan jasa akan mempengaruhi secara kuat pelanggan untuk membeli. Citra merek yang positif akan lebih mudah tersimpan di benak pembeli. Hal tersebut kondusif dengan temuan yang diperoleh Farisi (2018) dan Tubagus A (2020)yang memaparkan ternyata citra merek mampu memberikan dampak atau dampak positif pada kegiatan keputusan pembelian.

Nilai temuan ini membuktikan ternyata kualitas produk secara parsial berdampak positif dan relavan pada kegiatan keputusan pembelian Smartphone Oppo di Badilan Grosir Singaraja. Hal tersebut smaa dengan teori yang disampaikan oleh Kotler \& Keller (2012), produk yang berkualitas akan dapat memberikan pengaruh pada keputusan masyarakat agar membeli produk yang bersangkutan. Hal tersebut kondusif pula oleh temuan sebelumnya yang dilaksanakan oleh Sutanto \& Kaihatu ( 2019) dan Ilham et al., (2020), yang menjelaskan ternayat kualitas produk memiliki dampak yang relevan pada tindakan keputusan pembelian terjadinya peningkatan penjualan pada merek Smartphone Oppo karena kualitas dari produk tersebut dipercaya oleh konsumen atau melebihi harapan dan keinginan konsumen.

Penelitian mengenai dampak variabel desain produk pada keputusan pembelian, diperoleh hasil ternyata desain produk berdampak secara positif dan relevan pada keputusan pembelian Smartphone Oppo di Badilan Grosir Singaraja. Karena semakin menarik desain produk serta didukung oleh fitur yang menyesuaikan pada kebutuhan serta keinginan pembeli, kemungkinan dapat memberikan pengaruh terhadap pelanggan untuk membeli. Hal itu sama dengan teori
Jurnal Pendidikan Ekonomi Undiksha

Vol. 13 No. 2 (2021)

yang dipaparkan K. and Amstrong (2016), menjelaskan ternyata bentuk atau kemasan produk dapat menarik para perhatian pelanggan terhadap dilakukannya pembelian, jika desain produk itu dianggap baik oleh pelanggan. Hal berikut didukung dengan nilai temuan yang dilakukan Amron (2018) dan Ulfami (2020), memaparkan bahwa desain produk memberikan pengaruh positif dan relevan kepada keputusan pembelian.

Nilai temuan ini juga menunjukan ternyata $X_{1}$ dan $X_{2}$ serta $X_{3}$ berdampak posistif pada $Y$. Konsumen selalu memperhatikan elemen-elemen penting yang memberikan pengaruh keputusan pembelian seperti citra merek, kualitas produk,dan desain produk. Hal tersebut sama degan teori yang dipaparkan oleh memiliki elemen seperti desain produk, harga, citra merek dan kualitas produk yang membuat pelanggan ketika pembelian produk tertentu. Hal ini sama dengan hasil riset yang sudah dibuktikan Amron (2018) dan Sutanto \& Kaihatu (2019), yang memaparkan hasil penelitiannya bahwa citra merek dan kualitas produk serta desain produk memberikan dampak yang positif dan relevan pada kegiatan pembelian.

\section{SIMPULAN DAN SARAN}

Merujuk analisis data dan pembahasan dari hasil penelitian yang dillaksanakan, hingga bisa dirangkum bahwa (1) Secara parsial citra merek berdampak positif dan relevan pada keputusan pembelian Smartphone Oppo di Badilan Grosir Singaraja, (2) Secara parsial kualitas produk berdampak positif dan relevan pada keputusan pembelian Smartphone Oppo di Badilan Grosir Singaraja, (3) Secara parsial desain produk berdampak positif dan relevan pada keputusan pembelian Smartphone Oppo di Badilan Grosir Singaraja, (4) Secara bersamaan Citra Merek dan Kualitas produk serta Desain Produk berdampak positif dan relevan pada keputusan pembelian Smartphone Oppo di Badilan Grosir Singaraja.

Mengacu pada nilai pembahasan, dan simpulan yang sudah dipaparkan, sehingga bisa buat beberapa saran yaitu (1) 
Pada pihak manajemen Badianlan Grosir Singaraja, agar mampu mempertahankan dan meningkatkan ketertarikan dan kepercayaan konsumen sehingga banyak yang melakukan keputusan pembelian di Badilan Grosir Singaraja. Peningkatan keputusan pembelian dapat dilakukan melalui tetap menjaga citra baik perusahaan dan citra merek produk yang dijual, meningkatkan kulitas produk yang ditawarkan sehingga konsumen menjadi lebih yakin dan percaya untuk membeli, dan menyediakan desain Smartphone terbaru yang tentunya mampu menarik keingginan konsumen untuk membeli. Dengan hal tersebut diharapakan dapat mencapai target penjualan dari pihak perusahaan, (2) Bagi penemu selanjutnya, terutama yang ingin dan berminat untuk memahami mengenai $X_{1}, X_{2}$ dan $X_{3}$ serta $Y$ diharapkan bisa memperluas temuan ini dengan menambahkan sampel yang lebih banyak hingga bisa menguji variabel lainnya yang diperkirakan kuat bisa mempengaruhi keputusan pembelian seperti promosi, harga, fitur,kualitas pelayanan dan masih banyak variabel lainnnya.

\section{DAFTAR PUSTAKA}

Amron, A. (2018). The Influence Of Brand Image, Desain, Feature OnPurchasing Decision Of Apple iOS Smartphone In Surakarta,Indonesia. The International Journal of Social Sciences and Humanities Invention, 5(12), 51875191.

Amstrong, K. and. (2016). Principles of marketing. 16th Edition. Pearson Education Limited.

Amstrong, K. P. dan. (2012). prinsip - prinsip manajemen. In edisi 14 jilid 1. Indeks.

Farisi, S. (2018). Pengaruh Citra Merek dan Kualitas Produk terhadap Keputusan Pembelian Sepatu Adidas pada Mahasiswa Universitas Muhammadiyah Sumatera Utara. The National Conferencences Management and Business, 6(1), 689-705.

Ilham, A. ., H, S., \& T.H, U. (2020). The Influence of Product Quality, Price and Brand Image On Customer Satisfaction Through Purchasing Decisions (Case:
Hansaplast Koyo in Tangerang). Jurnal Internasional Pemasaran Dan Manajemen Bisnis, 5(2), 23-32.

Kotler, \& Keller. (2012). Marketing Managemen.(edisi14). Indeks.

Lubis, I. . D., \& Hidayat, R. (2017). Pengaruh Citra Merek dan Harga Terhadap Keputusan Pembelian pada Sekolah Tinggi IImu Manajemen Sukma Medan. 5(1), 15-24.

Maindoka, L. F., Altje, Tumbel, Christy, \& Rondonuwu. (2018). Analisis Pengaruh Citra Merek, Harga, dan Desain Produk terhadap Pembelian Mobil Nissan Grand Livina Pada PT.Wahana Wirawan Manado. Jurnal EMBA, 6(3), 1518-1527.

Margono. (2010). Metodelogi penelitian pendidikan. Rineka Cipta.

Mukarromah, D. ., \& R, C. (2019). . Pengaruh Citra Merek,Desain Produk Dan Kualitas Produk Terhadap Keputusan Pembelian Sepatu Bata. Jurnal Riset Manajemen Dan Bisnis Dewantara., 2(2), 27-36.

S, A., \& Aloan, A. (2017). Pengaruh Citra Merek, Harga, dan Kualitas Produk terhadap Keputusan Pembelian Handphone Merek Xiaomi di Kota Langsa. Jurnal Manajemen Dan Keuangan, 6(1), 660-669.

Shimp, T. . (2003). Periklanan Promosi Aspek Tambahan Komunikasi Pemasaran Terpadu. Jilid 1.Terj. Revyani Sahrial, Dyah Anikasari. Erlangga.

Subhash, C. J. (2017). Esentials of Global Marketing.USA. Sounth - Western College Publishin.

Sugiyono. (2007). Metodelogi Penelitian Bisnis. Edisi X. CV Alfabeta.

Sugiyono. (2014). Metode Penelitian Bisnis. Alfabeta.

Sutanto, J. ., \& Kaihatu, T. S. (2019). The Effect Of Product Design, Brand Image,And Product Quality Towards Purchasing Decisions Of Laptop Brands. 3(6), 113-125.

Syamsidar, R., \& Soliha, E. (2019). Kualitas Produk, Persepsi Harga, Citra Merek dan Promosi terhadap Proses Keputusan Pemeblian (Studi Pada Banaran 9 Coffe and Tea di 
Gemawang, Kabupaten Semarang). ..Jurnal Bisnis Dan Ekonomi, 26(2), 146-154.

Tengor, G. (2016). Pengaruh Merek, Desain Produk dan Kualitas Produk terhadap Keputusan Pembelian Iphone (Studi kasus pada Mahasiswa STIE Eben Haezar Manado). Jurnal Berkala IImiah Efisisensi, 16(04), 367-375.

Tubagus A, D. (2020). Effect Of Product Quality,Brand Image and Life Style Against Buying Decision. Journal of Management Science, 3(2), 51-57.

Ulfami, P. (2020). engaruh Desain Produk, Keragaman Produk, dan Harga terhadap keputusan pembelian pada online shop Giyomi Melalui Shopee. Jurnal Pendidikan Tata Niaga, 8(1), 702-708.

Yustiawan, O. (2016). Pengaruh Kualitas Produk, Harga, Dan Citra Merek Terhadap Keputusan Pembelain Honda Vario. Jurnal IImu Dan Riset Manajajemen, 5(2), 1-20. 